
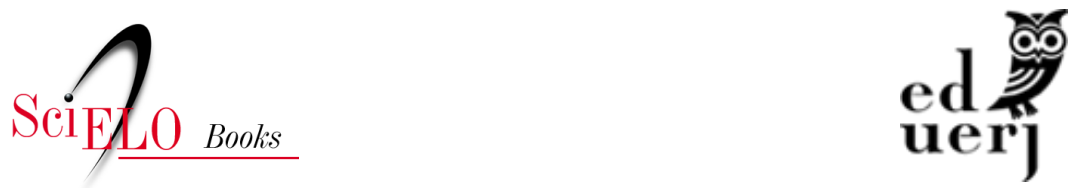

\title{
Metrópole em movimento: reflexões sobre a produção do espaço na região metropolitana do Recife a partir da localização dos empreendimentos do PMCMV
}

\author{
Luciana de Carvalho Gomes
}

\section{SciELO Books / SciELO Livros / SciELO Libros}

GOMES, L. C. Metrópole em movimento: reflexões sobre a produção do espaço na região metropolitana do Recife a partir da localização dos empreendimentos do PMCMV. In.: MAIA, D. S., and MARAFON, G. J., eds. $O$ programa Minha Casa Minha Vida: habitação e produção do espaço urbano em diferentes escalas e perspectivas [online]. Rio de Janeiro: EDUERJ, 2020, pp. 53-74. ISBN: 978-65-00-03029-7.

https://doi.org/10.7476/9786500030297.0003.

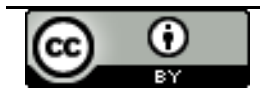

All the contents of this work, except where otherwise noted, is licensed under a Creative Commons Attribution 4.0 International license.

Todo o conteúdo deste trabalho, exceto quando houver ressalva, é publicado sob a licença Creative Commons Atribição 4.0.

Todo el contenido de esta obra, excepto donde se indique lo contrario, está bajo licencia de la licencia Creative Commons Reconocimento 4.0. 


\section{Metrópole em movimento: reflexóes sobre a produção do espaço na região metropolitana do Recife a partir da localização dos empreendimentos do PMCMV}

Luciana de Carvalho Gomes ${ }^{1}$

\section{Introdução}

O processo de urbanização no Brasil ocorreu de forma intensa e foi profundamente marcado pela desigualdade social. $\mathrm{O}$ rápido crescimento demográfico estabeleceu demandas cada vez mais urgentes por infraestrutura, serviços e moradia. $\mathrm{O}$ atendimento a estas necessidades foi pautado em um modelo de urbanização excludente e precário, especialmente nas capitais e regióes metropolitanas. Este desequilíbrio pode ser observado por índices econômicos e sociais, mas também pela forma diferenciada como o espaço urbano se apresenta. Conforme Santos et al (2014), tal distinção pode ser reconhecida visualmente, não somente pelo padrão edilício, mas pelas características de infraestrutura e serviços disponíveis em cada porção do território.

Historicamente, as áreas mais favoráveis da cidade foram ocupadas pelas classes abastadas, restando aos pobres os nichos centrais insalubres e de difícil ocupação, e as periferias. A história da ocupação das cidades é, portanto, a história da disputa por terra - quanto mais centrais e bem-servidas de in-

1 O presente trabalho foi realizado com apoio da Fundação de Apoio à Pesquisa do Estado da Paraíba- FAPESQ e da Coordenaçáo de Aperfeiçoamento de Pessoal de Nível Superior - Brasil (CAPES) - Código de Financiamento 001. 
fraestrutura, mais valorizadas e, por consequência, menos acessíveis aos mais pobres. De acordo com Villaça (2010), a terra urbana só interessa enquanto terra-localizaçáo, ou seja, enquanto meio de acesso a todo sistema urbano. A adequação da moradia passa, portanto, não apenas pelo local onde se encontra, mas pela sua relação socioespacial com o restante da cidade. Quanto mais frágeis as conexôes, maior a segregação.

No Brasil, a segregação socioespacial está intimamente vinculada à concentração de renda e de oportunidades. Por isso uma favela incrustada entre bairros valorizados náo deixa de ser uma área segregada, uma vez que os equipamentos e serviços do entorno podem não ser acessíveis econômica ou socialmente a seus moradores. Ao mesmo tempo, se esta área náo se encontra protegida por algum instrumento legal, como a ZEIS, por exemplo, a tendência é ela acabar absorvida pelo mercado especulativo e sua população original migrar para áreas mais afastadas. Por vezes, este deslocamento se dá por intervenção do poder público que por várias razóes (como risco geotécnico, alagamentos, reurbanização etc.) remove famílias para conjuntos habitacionais distantes do centro, onde a terra é mais barata. Estes movimentos geralmente forçosos alimentam o que muitos autores denominam periferização da pobreza.

A segregação também se evidencia em outro fenômeno urbano, intermediado pelo mercado imobiliário: os condomínios fechados. Apelando para o discurso do caos e da violência urbanos em contraponto à vida bucólica oferecida "fora" da cidade, o mercado sorveu parcela da população, cujo ideal de moradia se materializava nesses bairros elitizados e autossuficentes. Esses núcleos isolados conferiram um novo tipo de apropriação da terra, provocando uma descontinuidade urbana, em sua maioria não previstas pelos instrumentos de planejamento local. Isolados por muros e sistemas de segurança, esses espaços, ao mesmo tempo que afastam seus moradores da vida urbana, colaboram para a segregação socioespacial de seu entorno.

É importante, no entanto, distinguir tais fenômenos segregantes. Villaça (2010) aponta para dois tipos de segregação socioespacial. Uma delas é a voluntária, que se produz quando o indivíduo, por iniciativa própria, busca viver com outras pessoas de sua classe. A outra é a involuntária, quando pessoas se veem obrigadas, pelas mais variadas forças, a morar em um setor ou deixar de morar em um setor ou bairro da cidade. Embora Villaça, se refira à tendência das classes abastadas se concentrarem em uma única região urbana, o que ele chama de segregação voluntária ilustra a situação dos condomínios 
para onde a burguesia migra por vontade própria, ainda que impulsionada por uma efêmera sensação de proteção e convívio com a natureza, diferindo do caso dos mais pobres, que se veem coagidos pelo mercado imobiliário a viver ou deixar de viver em determinado local. Ou, nas palavras de Harvey (1976, apud Villaça, 2010), os ricos podem comandar o espaço, enquanto os pobres são prisioneiros dele.

A localizaçáo, portanto, pode incentivar ou privar as classes pobres na fruiçáo das oportunidades urbanas. O maior ou menor contato com essas oportunidades apontam para o nível de segregaçáo socioespacial de uma determinada população. Segundo Santos (1987),

[...] cada homem vale pelo lugar onde está, o seu valor como produtor, consumidor, cidadão depende de sua localização no território. [...] Pessoas com a mesmas virtualidades, a mesma formação, até o mesmo salário, tem valor diferente segundo o lugar onde vivem: as oportunidades não são as mesmas. Por isso a possibilidade de ser mais ou menos cidadãos depende, em larga produção, do ponto do território onde se está. (Santos, 1987)

Se a localização da moradia é um fator determinante para oportunizar a vida urbana, o deslocamento humano pode nos servir de indicador quanto ao nível de segregação (ou inserção) socioespacial de um determinado território. A extensão dos deslocamentos é consequência da distribuição, na malha urbana, da infraestrutura e dos serviços e atividades essenciais para a vida na cidade. Quanto mais equilibrada for a repartiçáo no espaço, menores seráo os deslocamentos e melhor será o acesso dessa população às amenidades urbanas. Ressalvamos que ter uma escola ao lado de casa, mas sem professores suficientes, terá pouco efeito no direito à educaçáo. Entendemos que a inclusão social tem múltiplas variantes, mas consideramos que ter acesso caminhando por cinco minutos, por exemplo, a um posto de saúde, é um bom indicativo de inserção socioespacial.

Nahas et al (2006), quando fala dos indicadores de qualidade de vida, afirma que para mensurar a equidade no acesso da populaçáo aos bens e recursos urbanos devem ser considerados tanto o aspecto espacial (acesso espacial) quanto o social (acesso social). $\mathrm{O}$ acesso social é fundamentalmente determinado pela condição social, como renda e escolaridade, entretanto, não se pode esquecer que este acesso depende também da distância existente entre o local de moradia e o local onde se dá a oferta dos bens e serviços. $\mathrm{Na}$ 
dimensão acesso espacial, a distribuição física da infraestrutura e dos serviços é, portanto, tão importante como a condiçáo do deslocamento (dificuldade ou facilidade) para alcançá-los.

Castells (2000) nos dá indicativos da importância dos deslocamentos humanos quando sustenta que a circulação, seja ela de mercadorias, informaçôes e, principalmente, de pessoas, é um dos fatores estruturais e estruturantes de uma região metropolitana, sendo o seu entendimento revelador das relaçóes entre os elementos da estrutura urbana, produção (trabalho), reprodução (moradia) e consumo. Villaça traz essa análise regional para os limites intraurbanos, afirmando que o espaço urbano é estruturado fundamentalmente pelas condiçóes de deslocamento do ser humano, seja enquanto portador da mercadoria força de trabalho (deslocamento casa-trabalho), seja enquanto consumidor (deslocamento casa-compras, casa- lazer, escola etc.). Acrescenta ainda que daí vem o poder estruturador intraurbano das áreas comerciais e de serviços do centro, por gerarem a maior quantidade de deslocamentos, pois acumulam os deslocamentos força de trabalho com consumidor.

Temos, então, a condiçáo do deslocamento enquanto elemento estruturador do espaço (intraurbano e metropolitano) e a condição de deslocamento como indicador de inserção socioespacial da moradia (local). Essas dimensóes se entrelaçam quando consideramos que o espaço urbano é produzido e consumido por um único processo (Villaça, 2010), o que Santos (2006) por sua vez, chama de totalidade. Em cidades desiguais como as nossas se torna mais evidente, pois a classe dominante comanda a apropriação das vantagens do espaço urbano, como a condição dos deslocamentos, piorando a dos demais.

A conquista de cidades menos segregadas requer, portanto, que a moradia ocupe o centro desta discussáo. A habitaçáo vista além da terra e de padróes construtivos mínimos, mas inserida em uma localização que ofereça acesso à infraestrutura, equipamentos, comércio e serviços urbanos. $\mathrm{O}$ estudo da adequação habitacional, portanto, implica o entendimento de seus componentes locacionais, enquanto protagonistas da inserção socioespacial urbana.

\section{A política habitacional no Brasil: da provisão de moradias ao direito à cidade}

O advento da indústria após a Segunda Guerra e a modernização das cidades, nos anos 1960, estimularam a migração campo-cidade. Até 1940, as ci- 
dades brasileiras continham apenas $32 \%$ da população (12,8 milhóes), 30 anos mais tarde, a população urbana superava a rural (52 milhōes). Atualmente nossas cidades abrigaram mais de 160 milhóes de habitantes (85\%). Em números absolutos, em menos de 50 anos, quase 110 milhōes de pessoas migraram para áreas urbanas. Este deslocamento humano massivo levou a uma alta demanda por terra urbana e consequentemente sua rápida valorização. $\mathrm{O}$ alto preço do solo acabou por conduzir os mais pobres a ocupar às áreas centrais renegadas pelo mercado imobiliário, como morros e alagados, e as periferias.

Algumas iniciativas governamentais tentaram amenizar esse quadro crítico. Sempre centralizadas pelo governo federal, as políticas de financiamento e produção de moradia surgem a partir dos anos 1940, com os Institutos de Aposentadoria e Pensão (IAP), mas ganham dimensão nacional apenas nos anos 1960, com a criação do Banco Nacional de Habitação (BNH). O BNH produziu 4 milhóes de unidades habitacionais em 22 anos de atuação. Conforme Cymbalista e Moreira (2006) apenas 33,6\% das unidades habitacionais do $\mathrm{BNH}$ foram destinadas aos setores populares, sendo que a populaçáo com rendimento entre um e três salários mínimos foi contemplada com menos de 6\% dos totais de unidades. Estes empreendimentos foram construídos geralmente em terrenos afastados do centro e desprovidos de serviços públicos. A contínua condição de exclusão da moradia (formal e informal) dará forma à pauta de reivindicaçóes dos movimentos sociais por reforma urbana e direito à cidade que vai alimentar as novas agendas públicas na redemocratizaçáo do país, como veremos a seguir.

Em 1986, o BNH é extinto e a Caixa Econômica Federal (CEF) passa a ser a operadora do FGTS. Segundo Cardoso e Aragão (2013), entre 1986 e 1994 vários órgãos se sucederam na gestão da política habitacional do governo federal, evidenciando uma forte instabilidade política e institucional que se estendeu até a criação do Ministério das Cidades, em 2003. Em paralelo, a luta das entidades civis e dos movimentos sociais em defesa do direito à terra urbana e à moradia se fortalecia culminando na inclusão dos artigos $182 \mathrm{e}$ 183, sobre política urbana na Constituição de 1988. Este foi um marco importantíssimo no reconhecimento da funçáo social da cidade e do direito à moradia. A regulamentação jurídica destes artigos, no entanto, veio apenas 13 anos mais tarde com a promulgação, em 2001, do Estatuto das Cidades (Lei 10257). O pleno desenvolvimento das funçóes sociais da cidade e da propriedade urbana passa a associar-se à garantia do direito à terra urbana, à 
moradia, ao saneamento ambiental, à infraestrutura urbana, ao transporte e aos serviços públicos, ao trabalho e ao lazer para todos.

Neste contexto, em 2003, foi criado o Ministério das Cidades com o objetivo de traçar uma política nacional de desenvolvimento urbano integrando a política habitacional com a de saneamento e transporte. Entre outras atribuiçóes, o MCidades tinha como objetivo a implantação do Sistema Nacional de Habitação de Interesse Social (SNHIS) e o Fundo Nacional de Habitação de Interesse Social (FNHIS). O Fundo era um pleito antigo do Movimento Popular por Moradia solicitado por meio de um projeto de lei apresentado à Câmara Federal em 1991, e que apenas foi atendido em 2005 com a Lei 11.124. Ela cria o SNHIS e o FNHIS com o objetivo de garantir acesso à terra urbanizada e habitação digna à população de menor renda e promover a articulação das instituiçôes e órgãos do setor habitacional nas diferentes esferas governamentais.

O SNHIS previa o compartilhamento da política nas três esferas de governo, fortalecendo o papel do município e da população local. Neste sentido, para aderir ao SNHIS e pleitear recursos do FNHIS foi exigido o desenvolvimento dos Planos Locais de Interesse Social (PLHIS) em consonância com o Plano Nacional de Habitação (PLANHAB), bem como a criação dos conselhos locais de gestores do fundo. $\mathrm{O}$ repasse dos recursos federais para a promoção da política habitacional em nível local (estados e municípios) passa então a ser realizado de maneira direta aos fundos locais, que por sua vez são geridos com a participação social, por meio do conselhos gestores. Os programas vinculados ao SNHIS foram o principal instrumento da política nacional de habitação até 2007.

Em 2008, o mundo entra numa crise iniciada pelo desequilíbrio do setor financeiro americano, a chamada crise dos subprime. Para minimizar os efeitos no Brasil, o governo federal adotou medidas de expansão do crédito pelos bancos públicos (Banco do Brasil, BNDES e Caixa Econômica), de forma a compensar a retração do setor privado, e medidas de caráter anticíclico, mantendo os investimentos em infraestrutura previstos no âmbito do PAC e mobilizando a Petrobrás no sentido de que também mantivesse os investimentos previstos (Adauto, 2013).

O Programa Minha Casa Minha Vida (PMCMV) surge em 2009, nesta conjuntura, como alternativa para incremento do mercado imobiliário para famílias com renda até 10 salários mínimos. Ao mesmo tempo que im- 
pulsionava a economia, atendia uma enorme demanda reprimida por habitação. O Programa acaba de completar dez anos e seus resultados são vultuosos. Com um orçamento superior a 430 bilhões de reais, contratou 5,3 milhóes de moradias, das quais já foram entregues 3,9 milhōes. ${ }^{2}$ Em 2015, com apenas seis anos de programa, já superava, em contrataçáo, as 4 milhôes de unidades habitacionais construídas pelo Banco Nacional de Habitaçáo (BNH), em 22 anos de atuação, e considerada até então, a política habitacional mais relevante do país.

O PMCMV trouxe o tema da moradia para o centro das discussóes sobre desenvolvimento urbano no país. Após 20 anos sem políticas nacionais de habitaçáo expressivas e uma longa luta dos movimentos sociais pelo direito à cidade e à moradia, o Estado se viu obrigado a (re)pensar a produçáo de seus territórios a partir da questão da moradia.

\section{O marco regulatório do PMCMV e a localizaçáo dos empreendimentos}

Segundo Lucena (2016), as diferenças de renda se traduzem no acesso desigual às infraestruturas e à terra urbana disponível e que esse tem sido um grande entrave para se garantir o direito à moradia no Brasil. Os programas habitacionais, por sua vez, historicamente estiveram dissociados de uma política fundiária e acabaram por reproduzir esse processo de exclusão pré-existente. Em uma lógica mercantil e imediatista, de uma maneira geral, os conjuntos habitacionais foram implantados em terrenos periféricos, não só por estes serem mais baratos, mas também para estabelecer novas áreas de valorização imobiliária. Nesta decisão desconsidera-se a falta de oportunidades urbanas destes locais e os custos posteriores a serem realizados (pelo poder público) para levar serviços e infraestrutura.

Como visto, houve um importante processo de estruturação da Política Urbana e Habitacional no país no primeiro mandato do Presidente Lula, com forte destaque à capacitação dos municípios e mensuração dos problemas habitacionais em nível local. No entanto, conforme Santos et al (2014), o uso de uma demanda social para atingir objetivos econômicos imediatos ocasionou uma pequena aderência entre o PMCMV e as açôes no setor habitacional implantadas. A maioria dos autores defende que este descolamento

2 Dados do sistema de monitoramento CAIXA MCMV, atualizado em agosto de 2018. 
ocorreu fundamentalmente devido o papel preponderante das construtoras na execução do programa e sua desarticulação com uma política fundiária (Araújo, 2013; Amore et al, 2015; Lucena, 2014; Cardoso e Aragão, 2013 e Rolnik, 2015).

As primeiras exigências referentes à localização dos empreendimentos foram estabelecidas pelo Decreto n. 7.499 de 2011, que regulamenta a Lei de criaçáo do PMCMV de 2009 (Lei n. ${ }^{0}$ 11.977/09). Neste documento, o PMCMV adota preceitos em consonância com o Planhab e o Estatuto da Cidade no que se refere a localização dos conjuntos. Estão entre os critérios de prioridade do PMCMV:

Art. $4^{\circ}$ Em áreas urbanas, deverão ser respeitados os seguintes critérios de prioridade para projetos do PMCMV, observada a regulamentação do Ministério das Cidades:

I- a doação pelos estados, pelo Distrito Federal e pelos municípios de terrenos localizados em área urbana consolidada para implantaçâo de empreendimentos vinculados ao programa;

II- a implementação pelos estados, pelo Distrito Federal e pelos municípios de medidas de desoneração tributária para as construçôes destinadas à habitação de interesse social; e

III- a implementação pelos municípios dos instrumentos da Lei no 10.257, de 10 de julho de 2001, que visam ao controle da retenção das áreas urbanas em ociosidade. (Grifo nosso)

O instrumento determinava ainda que os projetos contratados estivessem inseridos na malha urbana, em local dotado de infraestrutura básica e com condiçóes de acesso a serviços públicos essenciais, como transporte e coleta de lixo, e de equipamentos sociais, como escola, creches e postos de saúde.

A medida provisória 514 (posteriormente Lei n. ${ }^{\circ} 12.424 / 11$ ) estabeleceu que os empreendimentos deveriam ser implantados em terrenos localizados na malha urbana ou em áreas de expansão previstas nos planos diretores municipais; deveriam ainda dispor de infraestrutura básica, transporte público e contar com a existência de equipamentos e serviços de educação, saúde e lazer, ou com o compromisso do poder público de instalá-los ou ampliá-los quando inexistentes ou insuficientes. Permitiu-se também a inclusão de áreas destinadas a atividades comerciais nos projetos. 
Em 2013, torna-se obrigatório destinar áreas para implantação dos equipamentos públicos necessários ao atendimento da demanda gerada (Portaria n..$^{\circ}$ 518). O MCMV3 já traz alguns formulários quanto à localização do conjunto que, para pleitear a contratação, deverão estar explicitadas as distâncias para os equipamentos públicos mais próximos. Pouco a pouco, as regras do programa tentam restringir a implantação dos conjuntos a áreas menos periféricas.

Na prática, o que parece é que estes critérios não foram suficientes para coibir a lógica capitalista dos empreendedores privados. Diante do preço mais acessível da terra, o mercado imobiliário acabou optando por terrenos mais periféricos pela possibilidade de lucros maiores, mesmo nas cidades médias onde a especulação não é tão acirrada. Para as habitaçôes na faixa de interesse social (HIS), esta lógica se torna mais aguda, uma vez que o empreendimento é construído e vendido integralmente para a Caixa Econômica Federal, que o repassa aos beneficiários selecionados a partir de critérios pré-definidos pelo programa e pelas prefeituras. Desta forma, a incorporadora não precisa se preocupar em oferecer um local que atraia o "cliente".

Por outro lado, as normativas do Programa nos leva a crer que havia uma expectativa que os municípios protagonizassem o processo de definição da localizaçáo dos empreendimentos a partir dos instrumentos de planejamento desenvolvidos, tais como Plano Diretor e PLHIS, sem mencionar, por ora, os Planos locais de Saneamento, Resíduos Sólidos e Mobilidade que surgiram um pouco mais tarde, mas que igualmente deveriam subsidiar essas decisóes. Cardozo e Lago (2012) oferece uma explicação para isso, quando expóe que o desenho do Programa não articula efetivamente, de forma mandatória, esses procedimentos com a aprovação de projetos. A diretriz estabelecida na normativa toma a utilização dos instrumentos do Estatuto apenas como um critério de priorização.

A participaçáo dos municípios, de um modo geral, limitou-se a atender os parâmetros da lei de uso do solo local, muitas vezes flexibilizando-a para garantir a "viabilidade" do empreendimento, ainda que em detrimento de sua qualidade urbana. Para a faixa de interesse social, o município participou ainda com a indicação de demanda, e por vezes, com aporte em alguns empreendimentos, cujo valor da terra ou da moradia excedia o permitido pelo programa. A atuação do município priorizou a "desoneração" do setor privado, maximizando o lucro imobiliário da operação. Os efeitos territoriais deste 
processo têm sido alvo de vários estudos no Brasil, com os quais pretendemos colaborar aqui através de algumas reflexóes sobre seus impactos na Região Metropolitana do Recife (RMR).

\section{O PMCMV na Regiáo Metropolitana do Recife}

Segundo Souza et al (2015), a provisão de moradias na RMR ocorre historicamente por meio de três formas: da produção empresarial, da produção informal ou da promoção pública, onde a primeira define os padróes de organização social do território, estando, portanto, as demais subordinadas a ela. As tipologias resultantes deste processo, inseridos em um contexto de profundas desigualdades econômicas, evidenciam uma diferenciaçáo socioespacial que configura a RMR atual. Por meio de autoprodução ou dos conjuntos habitacionais produzidos pelo poder público a partir da década de 1960 , a periferização do Recife e a sua expansão para as cidades vizinhas se deram majoritariamente pela população de menor renda. Mais recentemente, o limitado território do Recife, no entanto, acabou por impulsionar também a metropolização da produção empresarial ávida pela valorização de novas áreas. É neste contexto metropolitano que surge o Programa Minha Casa Minha Vida (PMCMV), que além dos objetivos de superação da crise financeira já mencionados surgia como o principal programa de combate ao déficit habitacional.

De acordo com dados da Fundação João Pinheiro (2012), o Déficit Habitacional na Região Metropolitana do Recife (RMR), em 2009, quando foi lançado o PMCMV, era de 140.406 unidades habitacionais, correspondendo então a $5,5 \%$ do total de domicílios do estado e aproximadamente metade do déficit habitacional urbano de Pernambuco. Quase em sua totalidade encontrava-se em área urbana (99\%) e na faixa de renda de 0 a 3 salários (94\%). A coabitação e o ônus excessivo com aluguel constituíam a significativa maioria do déficit urbano, somando 87\%. Dos 14 municípios da RMR 3 , apenas quatro (Recife, Jaboatão dos Guararapes, Olinda e Paulista) atendem

\footnotetext{
3 Em janeiro de 2018, o município de Goiana passou a fazer parte da RMR, no entanto não seria possível sua comparação, pois náo foi considerada nas pesquisas referentes à RMR utilizada neste capítulo. Ressalvamos que a sua participaçáo no PMCMV Faixa 1 é de apenas 30 unidades e 117 unidades considerando todas as faixas, sendo, portanto, pouco influente nos resultados.
} 
por quase $80 \%$ do déficit, correspondendo a mais de 110 mil unidades em números absolutos. Ou seja, trata-se de um déficit associado à insuficiência de renda, majoritariamente urbano e concentrado nos municípios litorâneos do centro da RMR.

Mapa 1 - Localização dos municípios na RMR e no estado de Pernambuco

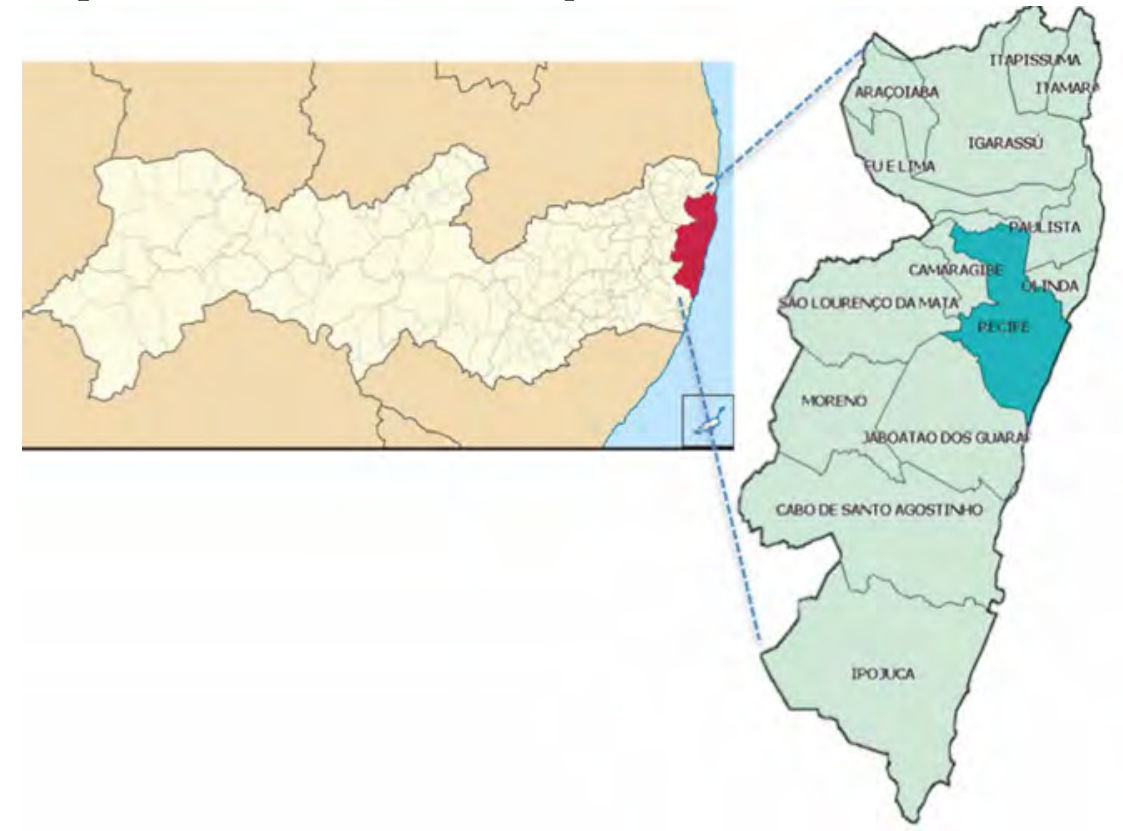

Fonte: https://pt.wikipedia.org/ e http://www.observatoriodasmetropoles.ufrj.br

Todos os municípios da RMR, com exceção de Araçoiaba, possuem empreendimentos do PMCMV (Tabela 1). No entanto, em todos eles, a maioria dos empreendimentos foram destinados às faixas de renda mais altas previstas no programa, famílias com rendimento até 9 mil reais. Apenas $24 \%$ das unidades habitacionais foram destinadas a famílias na faixa de renda mais baixa (Faixa 1), cujos rendimentos estão entre zero e 1,8 mil reais. Alguns municípios sequer possuem empreendimentos na Faixa 1, é o caso de Araçoiaba, Itapissuma e Camaragibe. Considerando todas as faixas de renda atendidas pelo programa, mais de 50 mil unidades habitacionais já foram entregues na RMR, e serão quase 84 mil considerando aquelas já contratadas. Ao observarmos os dados dos empreendimentos chamados Faixa 1, 
temos mais de 20 mil unidades contratadas, das quais cerca de 9 mil foram entregues.

Tabela 1 - Número de unidades habitacionais do PMCMV na RMR Todas as faixas

\begin{tabular}{|c|c|c|c|c|c|c|c|}
\hline $\begin{array}{c}\text { Setor da } \\
\text { RMR }\end{array}$ & Município & $\begin{array}{c}\text { Un. } \\
\text { Contratadas }\end{array}$ & $\begin{array}{c}\text { Un. } \\
\text { Entregues }\end{array}$ & $\begin{array}{l}\text { Un. Con- } \\
\text { tratadas } \\
\text { por Setor }\end{array}$ & $\begin{array}{c}\% \\
\text { Contrata- } \\
\text { das }\end{array}$ & $\begin{array}{l}\text { Un Entre- } \\
\text { gues por } \\
\text { Setor }\end{array}$ & $\begin{array}{c}\% \\
\text { Entregues }\end{array}$ \\
\hline \multirow{7}{*}{ NORTE } & $\begin{array}{l}\text { Abreu e } \\
\text { Lima }\end{array}$ & 2.875 & 2.861 & \multirow{7}{*}{38.949} & \multirow{7}{*}{$47 \%$} & \multirow{7}{*}{29.853} & \multirow{7}{*}{$59 \%$} \\
\hline & Araçoiaba & 0 & 0 & & & & \\
\hline & Itapissuma & 297 & 292 & & & & \\
\hline & Itamaracá & 1.144 & 1.058 & & & & \\
\hline & Olinda & 5.906 & 3.263 & & & & \\
\hline & Igarassu & 6.389 & 5.282 & & & & \\
\hline & Paulista & 22.338 & 17.097 & & & & \\
\hline \multirow{3}{*}{ OESTE } & Camaragibe & 5.168 & 2.727 & \multirow{3}{*}{13.321} & \multirow{3}{*}{$16 \%$} & \multirow{3}{*}{7.331} & \multirow{3}{*}{$15 \%$} \\
\hline & Moreno & 824 & 672 & & & & \\
\hline & $\begin{array}{l}\text { São Lou- } \\
\text { renço }\end{array}$ & 7.329 & 3.932 & & & & \\
\hline \multirow{3}{*}{ SUL } & Cabo & 3.447 & 465 & \multirow{3}{*}{25.685} & \multirow{3}{*}{$31 \%$} & \multirow{3}{*}{11.175} & \multirow{3}{*}{$22 \%$} \\
\hline & Ipojuca & 4.070 & 960 & & & & \\
\hline & Jaboatão & 18.168 & 9.750 & & & & \\
\hline CAPITAL & Recife & 5.746 & 2.035 & 5.746 & $7 \%$ & 2.035 & $4 \%$ \\
\hline \multirow{2}{*}{ TOTAL } & RMR & 83.701 & 50.394 & 83.701 & $100 \%$ & 50.394 & $100 \%$ \\
\hline & $\begin{array}{l}\text { Pernam- } \\
\text { buco }\end{array}$ & 200.683 & 136.204 & 200.683 & & 136.204 & \\
\hline
\end{tabular}

Fonte: Dados MCidades, abril/2019, elaborado pela autora 
Tabela 2 - Número de unidades habitacionais do PMCMV na RMR - Faixa 1

\begin{tabular}{|c|c|c|c|c|c|c|c|}
\hline $\begin{array}{c}\text { Setor da } \\
\text { RMR }\end{array}$ & Município & $\begin{array}{c}\text { Un. } \\
\text { Contrata- } \\
\text { das }\end{array}$ & $\begin{array}{c}\text { Un. } \\
\text { Entregues }\end{array}$ & $\begin{array}{l}\text { Un. Con- } \\
\text { tratadas } \\
\text { por Setor }\end{array}$ & $\begin{array}{c}\% \\
\text { Contrata- } \\
\text { das }\end{array}$ & $\begin{array}{l}\text { Un Entre- } \\
\text { gues por } \\
\text { Setor }\end{array}$ & $\begin{array}{c}\% \\
\text { Entregues }\end{array}$ \\
\hline \multirow{7}{*}{ NORTE } & \begin{tabular}{|l} 
Abreu e \\
Lima
\end{tabular} & 2.304 & 2.304 & \multirow{7}{*}{9.745} & & & \\
\hline & Araçoiaba & 0 & 0 & & & & \\
\hline & Itapissuma & 0 & 0 & & & & \\
\hline & Itamaracá & 553 & 500 & & $48 \%$ & 6.470 & $72 \%$ \\
\hline & Olinda & 3.000 & 1.551 & & & & \\
\hline & Igarassu & 1.504 & 1.267 & & & & \\
\hline & Paulista & 2.384 & 848 & & & & \\
\hline \multirow{3}{*}{ OESTE } & Camaragibe & 0 & 0 & \multirow{3}{*}{2.196} & & & \\
\hline & Moreno & 650 & 500 & & $11 \%$ & 570 & $6 \%$ \\
\hline & $\begin{array}{l}\text { Sao Lou- } \\
\text { renço }\end{array}$ & 1.546 & 70 & & & & \\
\hline \multirow{3}{*}{ SUL } & Cabo & 2.926 & 50 & \multirow{3}{*}{6.686} & & & \\
\hline & Ipojuca & 576 & 0 & & $33 \%$ & 1774 & $20 \%$ \\
\hline & Jaboatão & 3.184 & 1.724 & & & & \\
\hline CAPITAL & Recife & 1.608 & 192 & 1.608 & $8 \%$ & 192 & $2 \%$ \\
\hline \multirow[b]{2}{*}{ TOTAL } & RMR & 20.235 & 9.006 & 20.235 & $100 \%$ & 9.006 & $100 \%$ \\
\hline & $\begin{array}{l}\text { Pernam- } \\
\text { buco }\end{array}$ & 87.624 & 55.455 & 87.624 & & 55.455 & \\
\hline
\end{tabular}

Fonte: Dados MCidades, abril/2019, elaborado pela autora

Os empreendimentos da Faixa 1 de renda têm especial relevância no combate à pobreza na RMR, considerando que a população a que se destina compóe $94 \%$ do déficit habitacional, conforme já mencionado. A espacialização desses empreendimentos sobre o mapa de renda da RMR nos oferece os primeiros indícios de como está se dando a ocupação do território metropolitano. O Mapa 2 mostra que os empreendimentos da Faixa 1 estão localizados de maneira dispersa em todas as direçóes (norte, sul e oeste) da RMR, no entanto majoritariamente situados em áreas pobres e periféricas, 
em contraponto ao núcleo central historicamente com maior concentração de empregos e renda.

Mapas 2 - Renda por setor censitário e localização dos empreendimentos Faixa 1

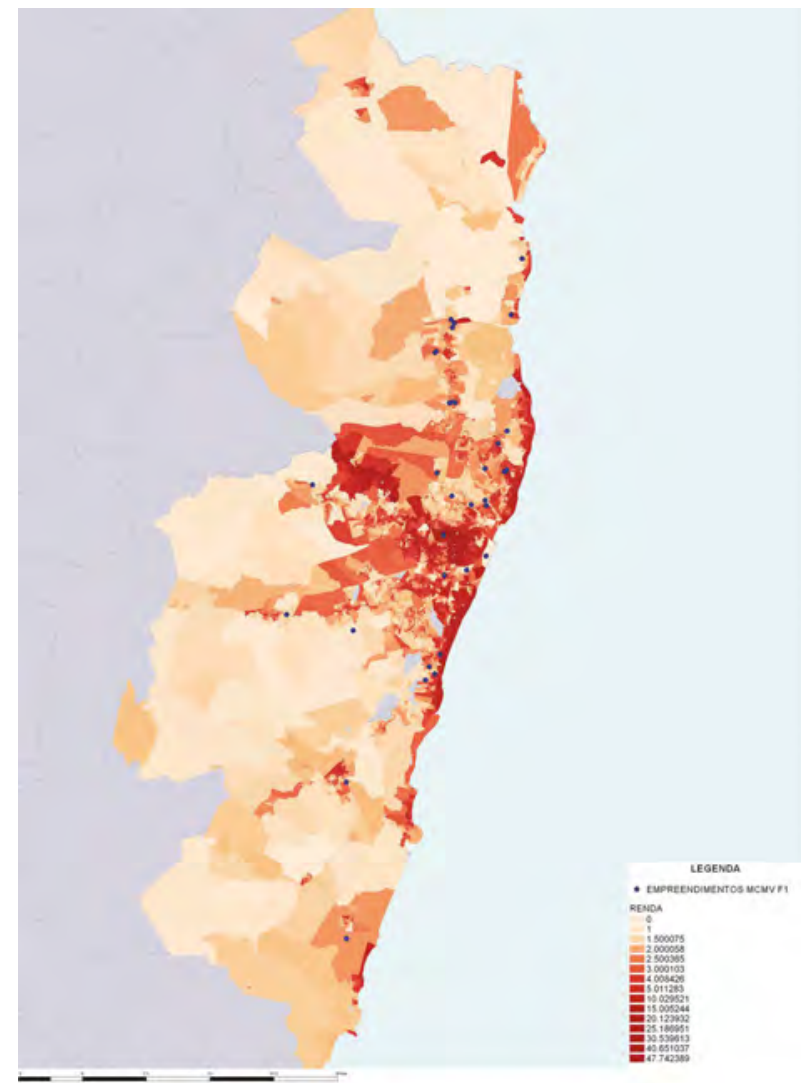

Fonte: Observatório das Metrópoles-Recife com base nos dados da CAIXA, 2019.

Elaboração: Luciana Gomes e André Lopes

O Mapa 3 nos traz a localização dos empreendimentos e os principais eixos viários da RMR, destacando, em branco, os núcleos urbanos. Podemos ver que a maioria dos terrenos escolhidos se encontram próximos a importantes eixos viários, como o formado pelas rodovias PE-15 e BR-101 norte, que atravessam vários municípios. Esta escolha não é aleatória, como explica Vilaça (2001), a via em si não provoca o crescimento urbano, ela oferece primeiro o aumento da acessibilidade, alterando, portanto, o valor da terra para além das estruturas construídas. 
A lógica de mercado da especulação de terrenos vazios ao longo de vetores de expansáo promissores antecede o PMCMV, no entanto, o que vemos é que o programa acaba por reforçá-la. Esta postura promove a maximizaçáo dos lucros do setor privado ao comprar terrenos mais baratos, ao mesmo tempo que estabelece novas áreas de valorizaçâo imobiliária. Em contraponto, desconsidera, nesta decisão, a falta de oportunidades urbanas destes locais, bem como os investimentos posteriores a serem realizados (pelo poder público) para levar serviços e infraestrutura. A expansão urbana neste contexto fortalece, portanto, o histórico processo de diferenciação do espaço urbano para ricos e pobres que caracteriza a RMR.

Mapa 3 - Localização dos empreendimentos Faixa 1 em relação aos núcleos urbanos e principais eixos de transporte

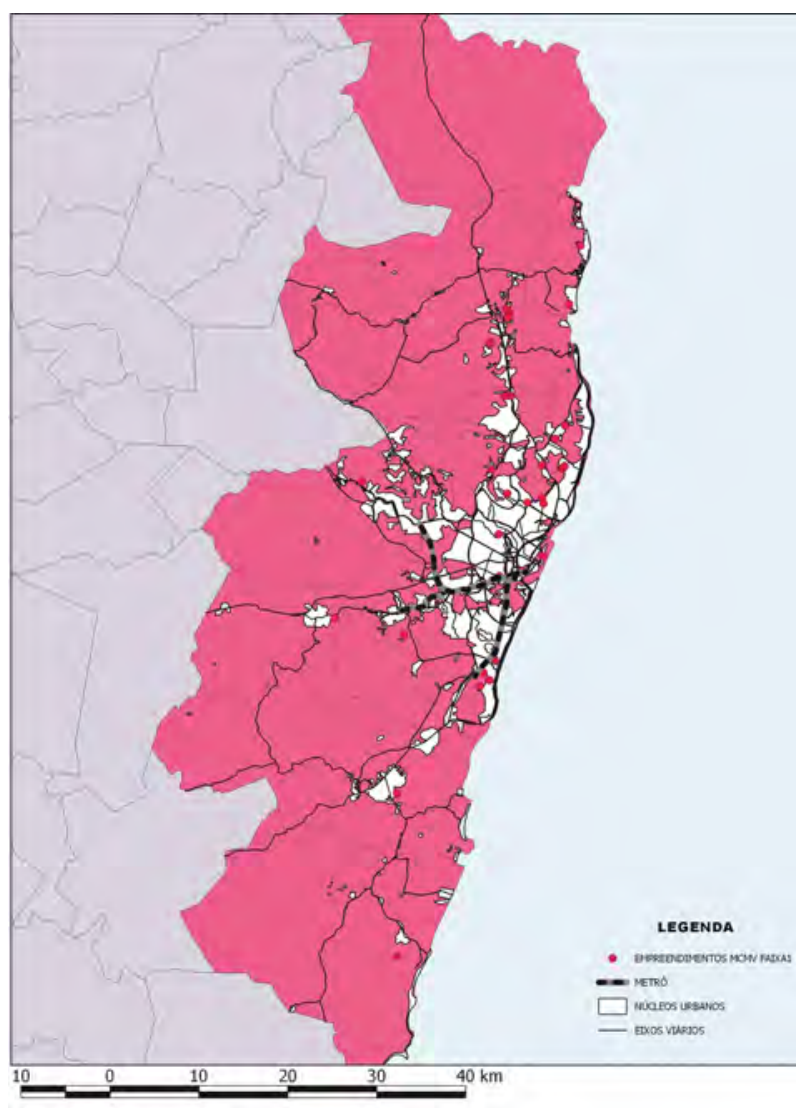

Fonte: Observatório das Metrópoles-Recife com base nos dados da CAIXA, 2019.

Elaboração: Luciana Gomes e André Lopes 
Retomando as Tabelas 1 e 2, podemos observar que a maioria das unidades da Faixa 1 entregues (72\%) encontram-se nos municípios ao norte da RMR. Este comportamento se repete para todas as faixas (com 59\%), indicando uma restruturação do território mais potente concentrada em um determinado setor. Além da questão associada ao preço da terra e ao lucro imobiliário, podemos afirmar que estes empreendimentos também foram impulsionados pela instalação de novas indústrias na região, como a fábrica de automóveis da Fiat e o Polo fármaco-químico.

De um modo geral, o setor sul apresenta, para todas as faixas, um desempenho mais lento nas entregas do que o setor norte. Ao sul da RMR predominam os residenciais voltados às faixas de renda maiores, provavelmente atraídos pela demanda criada com o surgimento de grandes empreendimentos, como o Complexo Portuário de SUAPE no Cabo de Santo Agostinho e o Estaleiro Atlântico Sul e a Refinaria Abreu e Lima, ambos em Ipojuca. Neste último município, as primeiras contrataçóes da Faixa 1 só ocorreram em 2018, ainda sem entrega. Jaboatáo do Guararapes, um dos municípios com alto déficit habitacional na RMR, se destaca como município do setor sul que mais atraiu empreendimentos do PMCMV em todas as faixas, no entanto executou apenas pouco mais da metade das unidades contratadas.

Entre os quatro municípios mencionados que mais contribuem com o déficit na RMR, Recife é o que apresenta pior desempenho. Na capital, cujo déficit supera 70 mil unidades, ${ }^{4}$ as primeiras 192 unidades da Faixa 1 foram entregues em 2018, bem como as demais contrataçôes, mencionadas na Tabela 2, foram efetivadas apenas em 2017. Isto evidencia, primeiro, que o programa não foi uma prioridade para a gestão local nos últimos anos, e segundo, indica uma postura do mercado da construçáo civil que, ao mesmo tempo que "desencoraja" a ocupação das áreas centrais pela populaçáo pobre, estimula a reorganização dos espaços metropolitanos prevendo os ganhos imobiliários atrelados a eles.

Embora uma relação direta exija estudos mais complexos, para efeito de escala observamos que o total de unidades construídas corresponde a cerca de $60 \%$ do déficit habitacional de 140.406 moradias apontado pela Fundação João Pinheiros para RMR em 2010 e quase 15\% deste universo, se con-

4 Déficit estimado pelo PLHIS de Recife, ainda em construção, é de 71.160 UH em 2017, disponível em https://habitatbrasil.org.br/wp-content/uploads/2018/10/Documento-S\%C3\%ADntese-LAB-Moradia-no-Centro-Recife.pdf 
siderarmos apenas a Faixa 1 de renda. Foram, portanto, avanços importantes, especialmente considerando as políticas habitacionais antecedentes. Porém, questiona-se: até que ponto este incremento de estoque impacta na redução das desigualdades de acesso às oportunidades urbanas enfrentadas pela populaçáo de baixa renda na metrópole?

No intuito de aproximar nossa discussão ao universo populacional, realizamos um comparativo demográfico simples. Utilizando a densidade populacional por domicílio média do estado, multiplicamos pelo número de moradias já entregues estimando a população beneficiada até o momento. Fizemos ainda cálculos relativos para entender o percentual de população já beneficiada, ou seja, que estâo residindo na moradia, e aquelas que virão a ser beneficiadas com a conclusão das unidades já contratadas (Tabelas 3 e 4).

Assim, estima-se mais de 173 mil pessoas ocupando novas localizações na RMR, impulsionadas por um único programa habitacional nos últimos 10 anos. Estes números devem chegar a cerca de 289 mil pessoas com a conclusão de todos os empreendimentos contratados. Milhares de novos trajetos desenhados para acessar ao trabalho, à escola, ao comércio e aos demais serviços. Os valores relativos são ainda mais impressionantes, uma vez que o número de beneficiários já atingiu o equivalente a mais de $10 \%$ da população total de alguns municípios. E logo serão mais de $20 \%$ desse universo, como nos casos de Igarassu, Paulista e São Lourenço.

Tabela 3 - Estimativa população beneficiada por município - Todas as faixas

\begin{tabular}{c|l|c|c|c|c|c|c|c}
\hline $\begin{array}{c}\text { Setor da } \\
\text { RMR }\end{array}$ & Município & $\begin{array}{c}\text { Populaçao } \\
\text { CENSO } \\
\mathbf{2 0 1 0}\end{array}$ & $\begin{array}{c}\text { Unids } \\
\text { Contrata- } \\
\text { das }\end{array}$ & $\begin{array}{c}\text { Unds. } \\
\text { Entregues }\end{array}$ & $\begin{array}{c}\text { Pop benefi- } \\
\text { ciada-con- } \\
\text { tratada* }\end{array}$ & $\begin{array}{c}\text { Pop con- } \\
\text { trat/ pop } \\
\text { total ** }\end{array}$ & $\begin{array}{c}\text { Pop. bene- } \\
\text { ficiada- en- } \\
\text { tregue* }\end{array}$ & $\begin{array}{c}\text { Pop } \\
\text { entreg/pop } \\
\text { total** }\end{array}$ \\
\hline & $\begin{array}{l}\text { Abreu e } \\
\text { Lima }\end{array}$ & 94.429 & 2.875 & 2.861 & 9.919 & $10,50 \%$ & 9.870 & $10,45 \%$ \\
\cline { 2 - 10 } & Araçoiaba & 18.156 & 0 & 0 & 0 & $0,00 \%$ & 0 & $0,00 \%$ \\
\cline { 2 - 10 } & $\begin{array}{l}\text { Itapissu- } \\
\text { ma }\end{array}$ & 23.769 & 297 & 292 & 1.025 & $4,31 \%$ & 1.007 & $4,24 \%$ \\
\hline & Itamaracá & 21.884 & 1.144 & 1.058 & 3.947 & $18,04 \%$ & 3.650 & $16,68 \%$ \\
\cline { 2 - 9 } & Olinda & 377.779 & 5.906 & 3.263 & 20.376 & $5,39 \%$ & 11.257 & $2,98 \%$ \\
\cline { 2 - 9 } & Igarassu & 102.021 & 6.389 & 5.282 & 22.042 & $21,61 \%$ & 18.223 & $17,86 \%$ \\
\cline { 2 - 9 } & Paulista & 300.466 & 22.338 & 17.097 & 77.066 & $25,65 \%$ & 58.985 & $19,63 \%$ \\
\hline
\end{tabular}




\begin{tabular}{l|l|c|c|c|c|c|c|c}
\hline \multirow{2}{*}{ OESTE } & $\begin{array}{l}\text { Camara- } \\
\text { gibe }\end{array}$ & 144.466 & 5.168 & 2.727 & 17.830 & $12,34 \%$ & 9.408 & $7 \%$ \\
\cline { 2 - 9 } & Moreno & 56.696 & 824 & 672 & 2.843 & $5,01 \%$ & 2.318 & $4 \%$ \\
\cline { 2 - 9 } & $\begin{array}{l}\text { Sao Lou- } \\
\text { renço }\end{array}$ & 102.895 & 7.329 & 3.932 & 25.285 & $24,57 \%$ & 13.565 & $13 \%$ \\
\hline \multirow{2}{*}{ SUL } & Cabo & 185.025 & 3.447 & 465 & 11.892 & $6,43 \%$ & 1.604 & $0,87 \%$ \\
\cline { 2 - 9 } & Ipojuca & 80.637 & 4.070 & 960 & 14.042 & $17,41 \%$ & 3.312 & $4,11 \%$ \\
\cline { 2 - 9 } & Jaboatáo & 644.620 & 18.168 & 9.750 & 62.680 & $9,72 \%$ & 33.638 & $5,22 \%$ \\
\hline \multirow{2}{*}{ CA P I - } & Recife & 1.537 .704 & 5.746 & 2.035 & 19.824 & $1,29 \%$ & 7.021 & $0,46 \%$ \\
\hline \multirow{2}{*}{ TOTAL } & \begin{tabular}{l} 
RMR \\
\cline { 2 - 9 } \\
\cline { 2 - 9 }
\end{tabular} & 3.690 .547 & 83.701 & 50.394 & 288.768 & $7,82 \%$ & 173.859 & $4,71 \%$ \\
\hline
\end{tabular}

Fonte: CENSO, 2010 e dados MCidades, abr. 2019, elaborado pela autora

* estimativa de beneficiados multiplicando o número de unidades pela média de moradores por domicílio em Pernambuco do CENSO 2010.

** percentual estimado dividindo o total de população beneficiada pelo PMCMV (considerando o total de unidades contratadas ou aquelas já entregues), pela população total do município conforme CENSO 2010.

Tabela 4 - Estimativa população beneficiada por município - Faixa 1

\begin{tabular}{|c|c|c|c|c|c|c|c|}
\hline $\begin{array}{c}\text { Setor da } \\
\text { RMR }\end{array}$ & Município & \begin{tabular}{|c} 
Unidades \\
Contratadas
\end{tabular} & $\begin{array}{l}\text { Unidades } \\
\text { Entregues }\end{array}$ & $\begin{array}{c}\text { Populaçáo } \\
\text { beneficiada- } \\
\text {-contratada* }\end{array}$ & $\begin{array}{l}\text { Pop contral } \\
\text { pop total }\end{array}$ & $\begin{array}{c}\text { Populacáo } \\
\text { beneficiada- } \\
\text { entregue* }\end{array}$ & $\begin{array}{l}\text { Pop entreg/ } \\
\text { pop total } * *\end{array}$ \\
\hline \multirow{7}{*}{ NORTE } & $\begin{array}{l}\text { Abreu e } \\
\text { Lima } \\
\end{array}$ & 2.304 & 2.304 & 7949 & $8,42 \%$ & 7949 & $8,42 \%$ \\
\hline & Araçoiaba & 0 & 0 & 0 & $0,00 \%$ & 0 & $0,00 \%$ \\
\hline & Itapissuma & 0 & 0 & 0 & $0,00 \%$ & 0 & $0,00 \%$ \\
\hline & Itamaracá & 553 & 500 & 1908 & $8,72 \%$ & 1725 & $7,88 \%$ \\
\hline & Olinda & 3.000 & 1.551 & 10350 & $2,74 \%$ & 5351 & $1,42 \%$ \\
\hline & Igarassu & 1.504 & 1.267 & 5189 & $5,09 \%$ & 4371 & $4,28 \%$ \\
\hline & Paulista & 2.384 & 848 & 8225 & $2,74 \%$ & 2926 & $0,97 \%$ \\
\hline \multirow{3}{*}{ OESTE } & \begin{tabular}{|l}
$\begin{array}{l}\text { Camara- } \\
\text { gibe }\end{array}$ \\
\end{tabular} & 0 & 0 & 0 & $0,00 \%$ & 0 & $0,00 \%$ \\
\hline & Moreno & 650 & 500 & 2.243 & $3,96 \%$ & 1.725 & $3,04 \%$ \\
\hline & $\begin{array}{l}\text { Sao Lou- } \\
\text { renco }\end{array}$ & 1.546 & 70 & 5.334 & $5,18 \%$ & 242 & $0,23 \%$ \\
\hline \multirow{3}{*}{ SUL } & Cabo & 2.926 & 50 & 10.095 & $5,46 \%$ & 173 & $0,09 \%$ \\
\hline & Ipojuca & 576 & 0 & 1.987 & $2,46 \%$ & 0 & $0,00 \%$ \\
\hline & Jaboatão & 3.184 & 1.724 & 10.985 & $1,70 \%$ & 5.948 & $0,92 \%$ \\
\hline
\end{tabular}




\begin{tabular}{l|l|c|c|c|c|c|c}
\hline CAPITAL & Recife & 1.608 & 192 & 5548 & $0,36 \%$ & 662 & $0,04 \%$ \\
\hline \multirow{2}{*}{ TOTAL } & RMR & 20.235 & 9.006 & 69.811 & $1,89 \%$ & 31.071 & $0,84 \%$ \\
\cline { 2 - 8 } & Pernambuco & 87.624 & 55.455 & 302.303 & $3,44 \%$ & 191.320 & $2,18 \%$ \\
\hline
\end{tabular}

Fonte: CENSO, 2010 e dados MCidades, abr. 2019, elaborado pela autora

* estimativa de beneficiados multiplicando o número de unidades pela média de moradores por domicílio em Pernambuco do CENSO 2010.

** percentual estimado dividindo o total de população beneficiada pelo PMCMV (considerando o total de unidades contratadas ou aquelas já entregues), pela população total do município conforme CENSO 2010.

Considerando apenas a Faixa 1, estima-se, em um futuro breve, quase 70 mil pessoas vivendo em novas localizaçóes. Apesar de resultados absolutos mais modestos, este universo tem especial impacto nas estruturas urbanas por sua maior dependência dos serviços públicos e, em especial, do transporte público. Neste sentido, observa-se uma quantidade relativa de população beneficiada bastante expressiva nos municípios de Abreu e Lima, Itamaracá, Igarassu e, futuramente, São Lourenço e Cabo, superando 5\% da população total destes municípios (Tabela 4).

O setor norte da RMR (Olinda, Paulista, Abreu e Lima, Igarassu e Itapissuma) foi o que apresentou maior número de famílias ocupando novas localizaçóes em seus territórios e nos traz algumas evidências sobre os impactos do programa na estrutura urbana. São municípios com baixo desenvolvimento econômico e social e um crescimento historicamente desarticulado do planejamento urbano. Alguns estáo ganhando certa dinâmica com o surgimento de novos equipamentos, como shoppings e faculdades particulares e algumas plantas industriais, mas todos ainda guardam grande dependência do Recife, tanto na produção quanto no consumo.

Os deslocamentos para satisfazer suas necessidades cotidianas no território metropolitano são, portanto, significativos. Conforme Andrade et al (2015), nos municípios de Abreu e Lima, Camaragibe, Olinda, Paulista e São Lourenço da Mata, em média 45\% dos trabalhadores necessitam se deslocar diariamente para outros municípios, pois residem em cidades-dormitórios. Não só a localização da população e seus destinos rotineiros configuram as crescentes demandas de transporte, mas também a renda destes grupos, uma vez que população de menor renda tende a usar mais o transporte público e fazer deslocamentos a pé.

O tempo médio nas viagens pendulares na RMR aumentou de $33 \mathrm{mi}$ nutos, em 1997, para 41 minutos, em 2010 e aumentou de 12,1\% para 
19,0\% o número de trabalhadores cujo tempo de viagem supera uma hora. Este fenômeno ocorreu em praticamente todos os municípios da RMR, mas com intensidade mais forte nos municípios periféricos, entre eles Abreu e Lima e Itapissuma. (Andrade et al, 2015). As longas distâncias casa-trabalho a serem percorridas por estas famílias, especialmente as da Faixa 1, nos indicam que o desequilíbrio na estrutura urbana metropolitana tende a ser reforçado pela expansão habitacional promovida pelo PMCMV. A distribuição periférica e dispersa da moradia associada à concentração de empregos em determinadas áreas onera o poder público que assume o ônus de expandir a oferta de infraestrutura e serviços urbanos (além de oportunidade de trabalho) a grandes extensóes territoriais. Bem como estabelece, na escala regional, uma urgência no que se refere à mobilidade, que extrapola o aspecto social e imprime entraves à própria economia da metrópole.

Apesar das melhorias da moradia em aspectos como pavimentação, drenagem, esgoto, luz e água, o fator localização amplia a vulnerabilidade dos moradores, quando eles passam a viver longe das oportunidades urbanas. Em que pese seu impacto na vida das pessoas (e de modo acumulativo, no espaço urbano), esse fator não é considerado nas estatísticas oficiais que subsidiam as políticas públicas voltadas para a habitaçáo. Os dados da Fundação João Pinheiro adotados, que servem de referência para vários programas de governo (como o PMCMV), por exemplo, não comportam esse tema. Sua metodologia visa principalmente mensurar a deficiência de estoque. Mesmo os indicadores de inadequação de domicílios se limitam a questôes de infraestrutura para servir à moradia e de titularidade do imóvel. Náo se trata de uma crítica à metodologia, mas apenas uma provocação sobre a construção de um discurso, cujas lacunas favorecem, antes de tudo, a produçáo empresarial. Precisamos de novos indicadores que o complementem ou até mesmo o contraponham. Considerar o fator localização no universo das necessidades habitacionais e o seu impacto na vida das pessoas é fundamental para romper o ciclo segregacionista de nossa urbanizaçáo, sobretudo pautando a revisáo das políticas públicas voltadas ao uso e ocupação do solo. 


\section{Consideraçóes finais}

A localização dos empreendimentos do PMCMV na RMR estão antes subordinadas aos interesses da produção empresarial da moradia do que à real demanda do déficit habitacional ou a capacidade de oferta de infraestrutura dos municípios. Alimentam, assim, uma lógica segregacionista, na qual o agente privado determina onde vivem ricos e pobres. As localizaçóes periféricas (definidas pela produção empresarial) das moradias acabam por transformar, em primeiro plano, o espaço urbano municipal (formal ou informalmente) diante das necessidades de produção, reprodução e consumo dos moradores. Não obstante, para além das questóes locais, a concentração de empregos e serviços nos municípios centrais, afastados dos conjuntos habitacionais, reforça a necessidade de tratamento do tema do transporte público em uma escala metropolitana.

Em um sentido mais amplo, observamos que a organização espacial desses empreendimentos implica em uma transformação na dinâmica espacial de milhares de famílias que passaram a residir em novas localizaçóes. Como vimos, a circulação de pessoas é um elemento estruturador e estruturante do espaço (intraurbano e metropolitano), o olhar, portanto, sobre o universo de moradores para além da moradia (inanimada) buscou aqui lançar alguns indícios sobre os impactos do PMCMV no território, considerando essa dimensão. A rápida transformação local com a chegada do empreendimento e, portanto, de milhares de famílias, quase sempre náo corresponde a respostas imediatas do poder público, que afinal não é o contratante e não tem assumido, neste caso, o protagonismo do uso e da ocupaçáo do solo em seus territórios.

Por fim, esclarecemos que as reflexóes aqui apresentadas impulsionaram uma pesquisa em andamento, de âmbito acadêmico. São fruto, sobretudo, de inquietaçóes diante da condição de isolamento destes conjuntos habitacionais periféricos, que apesar dos esforços financeiros, políticos e humanos vultuosos, mantêm a vulnerabilidade de seus moradores, ainda que sob um novo aspecto. Buscamos seguir refletindo sobre até que ponto estamos trocando um déficit habitacional por uma inadequação socioespacial que apenas vem alimentar as assimetrias de nossas cidades. 


\section{Referências}

ANDRADE, Mauricio et al. "Mobilidade urbana no contexto da organizaçáo social do território da Regiāo Metropolitana do Recife". In: Souza, M. Angela e Biton, Jan (orgs.) Recife: transformaçôes na ordem urbana. Rio de Janeiro: Letra Capital, 2015

AMORE, Caio Santo et al (orgs.) Minha Casa... E a Cidade? Rio de Janeiro: Letra Capital, 2015.

CYMBALISTA, Renato e MOREIRA, Tomás. "Política Habitacional no Brasil: a história e os atores de uma narrativa incompleta". In: Participação popular em políticas públicas: espaço de construção da democracia brasileira. - São Paulo: Instituto Pólis, 2006. 124p

CARDOSO, Adauto Lúcio e ARAGÃO, Thêmis Amorim. "Do fim do BNH ao Programa Minha Casa Minha: 25 anos da política habitacional no Brasil". In: CARDOSO, Adauto Lúcio (org.). O Programa Minha Casa Minha Vida e seus efeitos territoriais. Rio de Janeiro: Letra Capital, 2013.

CARDOSO, Adauto Lúcio e LAGO, Luciana Côrrea do. "O Programa Minha Casa Minha Vida e seus efeitos territoriais". In: CARDOSO, Adauto Lúcio (org.). O Programa Minha Casa Minha Vida e seus efeitos territoriais. Rio de Janeiro: Letra Capital, 2013.

CASTELLS, M. A questão urbana. Rio de Janeiro: Paz e Terra, 2000.

FJP - Fundação João Pinheiro, Centro de Estatística e Informaçôes. Déficit habitacional no Brasil 2009. Belo Horizonte, 2012. 200p.

LUCENA, Wilma Guedes de. A produção do espaço urbano da cidade de Patos - PB: do BNH ao Programa Minha Casa Minha Vida. (Dissertação). João Pessoa: Universidade Federal da Paraíba, 2014.

NAHAS, M.I.P. et al. "Metodologia de construção do Índice de Qualidade de Vida Urbana dos municípios brasileiros (IQVU-BR)". In: XV Encontro Nacional de Estudos Populacionais da Associação Brasileira de Estudos Populacionais, 2006, Caxambu, MG. Anais do XV Encontro Nacional de Estudos Populacionais da Associação Brasileira de Estudos Populacionais, 2006.

ROLNIK, Raquel et al. "O Programa Minha Casa Minha Vida nas regióes metropolitanas de São Paulo e Campinas: aspectos socioespaciais e segregação”. Cad. Metrop. São Paulo, v. 17, n. 33, pp. 127-54, maio 2015. Acesso em: mar. 2017. Disponível em: http://www. scielo.br/scielo.php?script=sci_arttext\&pid=S2236-99962015000100127\&lng=pt\&nr $\mathrm{m}=$ iso\&tlng=pt.

SANTOS, J.M et al. "Habitaçáo e Localização: Notas sobre padrōes de deslocamento em empreendimentos do PMCMV no Rio de Janeiro". Habitar 2014, nov. 2014.

SANTOS, Milton. O Espaço do Cidadão. São Paulo: Nobel, 1987.

SOUZA, M. Ângela et al. "As formas de provisão da moradia na configuração socioespacial da Regiáo Metropolitana do Recife". In: SOUZA, M. Angela e BITON, Jan (orgs.) Recife: transformaçôes na ordem urbana. Rio de Janeiro: Letra Capital, 2015

VILLAÇA, Flávio. Espaço intraurbano no Brasil. São Paulo: FAPESP, 2001. 